\title{
PROGNOSTIC FACTORS FOR PREDICTING VISUAL OUTCOME AFTER VITRECTOMY FOR POSTERIOR SEGMENT INTRAOCULAR FOREIGN BODIES
}

\author{
Ahmed M. Alyan ${ }^{1 *}$, Mahmoud A. Aswad MD ${ }^{1}$, Sherif A. Dabour MD ${ }^{1}$, Hassan Z. Hanefa MD \\ ${ }^{I}$ Ophthalmology Department, Faculty of Medicine, Zagazig University
}

Corresponding author:

Name: Ahmed M. Alyan

Email:

ahmedalyan30@yahoo.com

\section{ABSTRACT}

AIM: To analyze the prognostic factors and assess the visual outcome in patients with IOFBs treated by pars plana vitrectomy.

PATIENTS AND METHODS: This study was a prospective interventional case series of 80 consecutive eyes of patients with penetrating eye injuries and retained intraocular foreign body (IOFB) in the posterior segment who underwent IOFB removal by pars plana vitrectomy at Zagazig University Hospitals between August 2013 and December 2015. Three different groups were categorized according to final BCVA. Various preoperative, operative, and postoperative Factors were analyzed for their prognostic value for a good visual outcome and a poor visual outcome.

RESULTS: There were 74 males and 6 females with a mean age of $28.80 \pm 7.82$ years. Hammering and chiseling were the most frequent source of injury occurred in 69 patients $(86.25 \%)$. Final best corrected visual acuity (BCVA) was equivalent to or more than 0.5 (good outcome) in 28 patients, between $0.1-0.4$ in 20 patients and less than 0.1 (poor outcome) in 32 patients. Age, sex of patients and preoperative retinal detachment (RD) were statistically insignificant for visual outcome. Initial poor BCVA was found to be highly significant for poor final BCVA $(\mathrm{p}<0.001)$. Corneoscleral entry site and intraretinal FB location were found to be highly significant for poor visual outcome $(p<0.001)$. Corneal entry site and IOFBs finally located in vitreous cavity were highly significant for good outcome $(\mathrm{p}<0.001)$. Presence of preoperative endophthalmitis and postoperative RD were found to be significant for poor visual outcome ( $\mathrm{p}=0.037,0.006$ respectively).

CONCLUSIONS: Many prognostic factors were recognized which aid in predicting visual outcome and identifying which patients are at highest risk for visual loss. Initial BCVA, FB entry site and location, preoperative endophthalmitis and postoperative $\mathrm{RD}$ were the most significant prognostic factors in predicting visual outcome.

KEYWORDS Prognostic factors; intraocular foreign body; pars plana vitrectomy

\section{INTRODUCTION}

O cular injury caused by intraocular foreign bodies (IOFBs) is one of the most frequent causes of visual loss. Forty percent of patients with open globe injuries harbor at least one IOFB ${ }^{[1-3]}$.

Pars plana vitrectomy for posterior segment IOFBs is preferred because it enables direct viewing and controlled removal of the IOFB. Also, removal of vitreous hemorrhage by vitrectomy prevents inflammatory and fibrous reactions that may induce PVR and tractional detachment. Moreover it enables good viewing of the retina facilitating managment of retinal breaks. Pars plana vitrectomy (PPV) for the removal of IOFB proved to reduce the risk of endophthalmitis ${ }^{[4]}$.Prompt and full assessment of patients with possible IOFB retention is important to provide an effective therapeutic plan, intraoperative guidance, prognosis and counseling ${ }^{[5]}$.

The objective of this study was to analyze the prognostic factors and to assess the visual outcomes in patients with retained IOFBs managed by Pars plana vitrectomy.

\section{SUBJECTS AND METHODS}

This prospective interventional case series study included 80 consecutive eyes of 80 
patients with open-globe injuries (full thickness wound of the eyeball) and retained IOFB in the posterior segment. The patients who met the eligibility criteria underwent posterior segment IOFB removal at Zagazig University Hospitals between August 2013 and December 2015. Written informed consent was taken from every participant for surgery and for participation in the study. In cases of children, the consent was assigned by their parents. The study was accepted by scientific committee of Zagazig University. Patients with anterior segment IOFBs, initial visual acuity of no perception of light, optic nerve damage, and insufficient follow-up (less than 6 months) were excluded from the study.

\section{Preoperative patient preparation}

All patients underwent full history including age, sex, occupation, residence, mechanism of injury, timing of injury and previous vision, if known. Unaided and best corrected visual acuity (BCVA) whenever possible was measured. Slit lamp biomicroscopy of the anterior segment was performed. Fundus examination using indirect ophthalmoscope and slit lamp biomicroscopy was done to demonstrate the site of IOFB, presence of vitreous hemorrhage or retinal detachment (RD). Orbital computed tomography (axial and coronal) with minimal cuts of 1 to 1.5 $\mathrm{mm}$ was done and ophthalmic ultrasonography (A \& B scan) was done whenever possible.

\section{Initial surgical procedure:}

All surgeries were done under general anesthesia. Removal of IOFB was done on the first week after the accident in cases complicated by endophthalmitis, RD or traumatic cataract with ruptured lens capsule and secondary glaucoma, otherwise surgery were done on the second week. In patients with visually significant cataract, IOL calculation of the injured eye was performed.
If IOL calculation was not possible on the injured eye, the other non injured eye measurements were used and phacoemulsification was done followed by foldable intraocular lens implantation prior to IOFB removal ${ }^{[5]}$.

\section{Surgical procedures}

Preoperative preparation of the globe was followed by careful lid speculum placement. In patients with significant cataract, phacoemulsification was done before vitrectomy. A standard three-port PPV using Oertli OS3 machine (Oertli instrumente AG, Berneck, Switzerland) was then performed using a 20-G cutter. A wide-viewing system $\mathrm{BIOM}$ or resight viewing system (Carl Zeiss meditec AG, Oberkochen, Germany) was used. Posterior vitreous detachment was performed when it was not detached by active suction of vitreous cutter over the area of optic disc. Before removal of the IOFB, adhesions around the IOFB were removed and it was released from encapsulation (figure 1). The IOFB was then grasped using Grieshaber pannarale Basket forceps (Alcon,Fort worth,Texas,USA) (figure 2), and while the IOFB was removed through the sclerotomy an external earth magnet was applied close to the sclerotomy to prevent its slippage from the forceps and falling down onto the macula or optic disc (figure 3 ). If retinal tear(s) was present, it was treated with endolaser photocoagulation (figure 4). In cases of concurrent endophthalmitis, intravitreal vancomycin $(1 \mathrm{mg} / 0.1 \mathrm{ml})$ and ceftazidime $(2.25 \mathrm{mg} / 0.1 \mathrm{ml})$ were injected at the end of surgery. Fluid air exchange and silicon oil injection was done in cases of associated RD or retinal tears. Closure of sclerotomies and conjunctiva were done using 7-0 Vicryl sutures; and $2 \mathrm{mg}$ dexamethasone and $2 \mathrm{mg}$ gentamicin sulphate were injected subconjunctivally. 

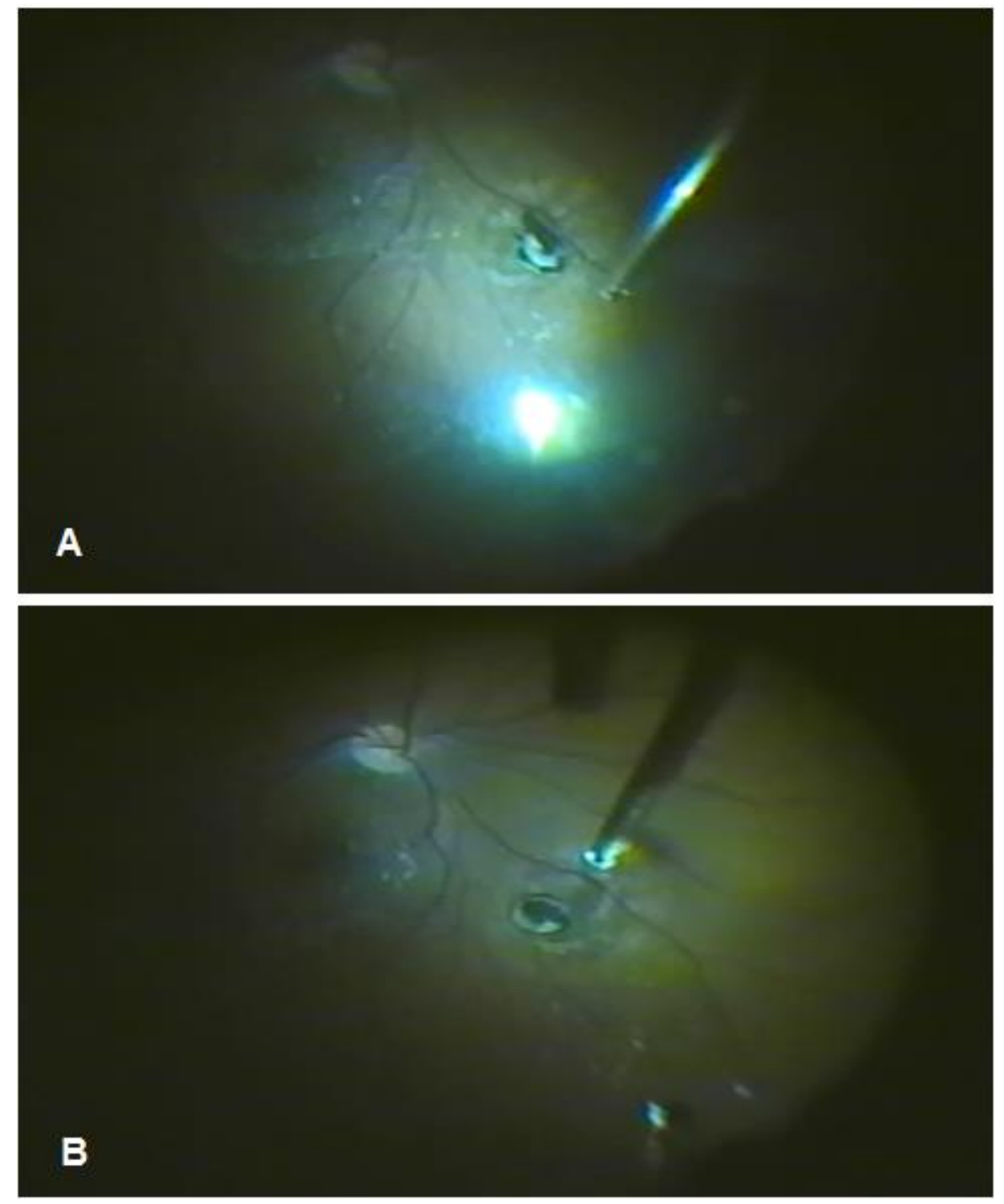

Figure 1: A, Release of adhesions around the intraocular foreign body. B, All adhesions around the foreign body is released. 

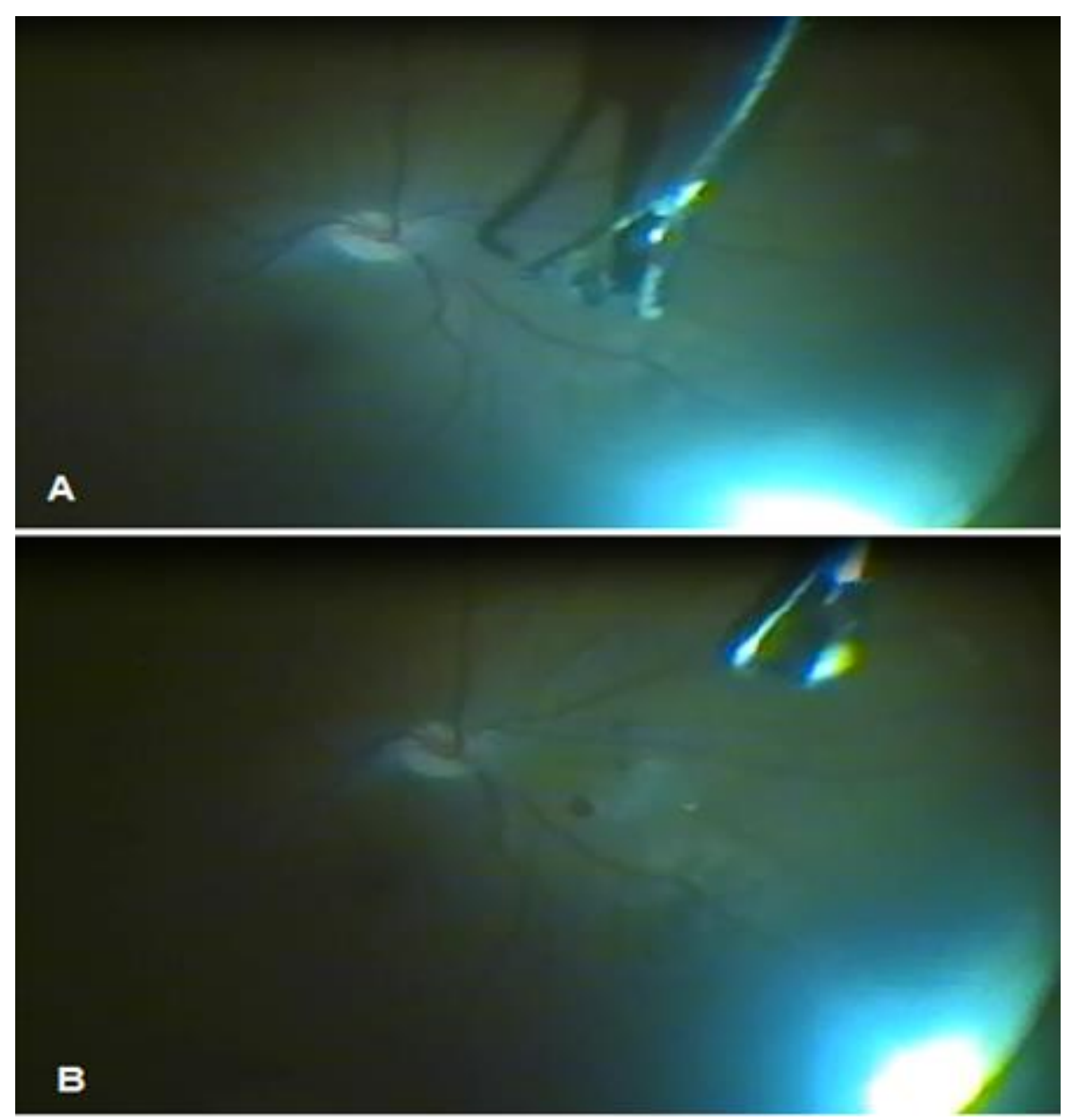

Figure 2: A, The IOFB before grasping with Basket forceps. B, The IOFB is grasped with Basket forceps.

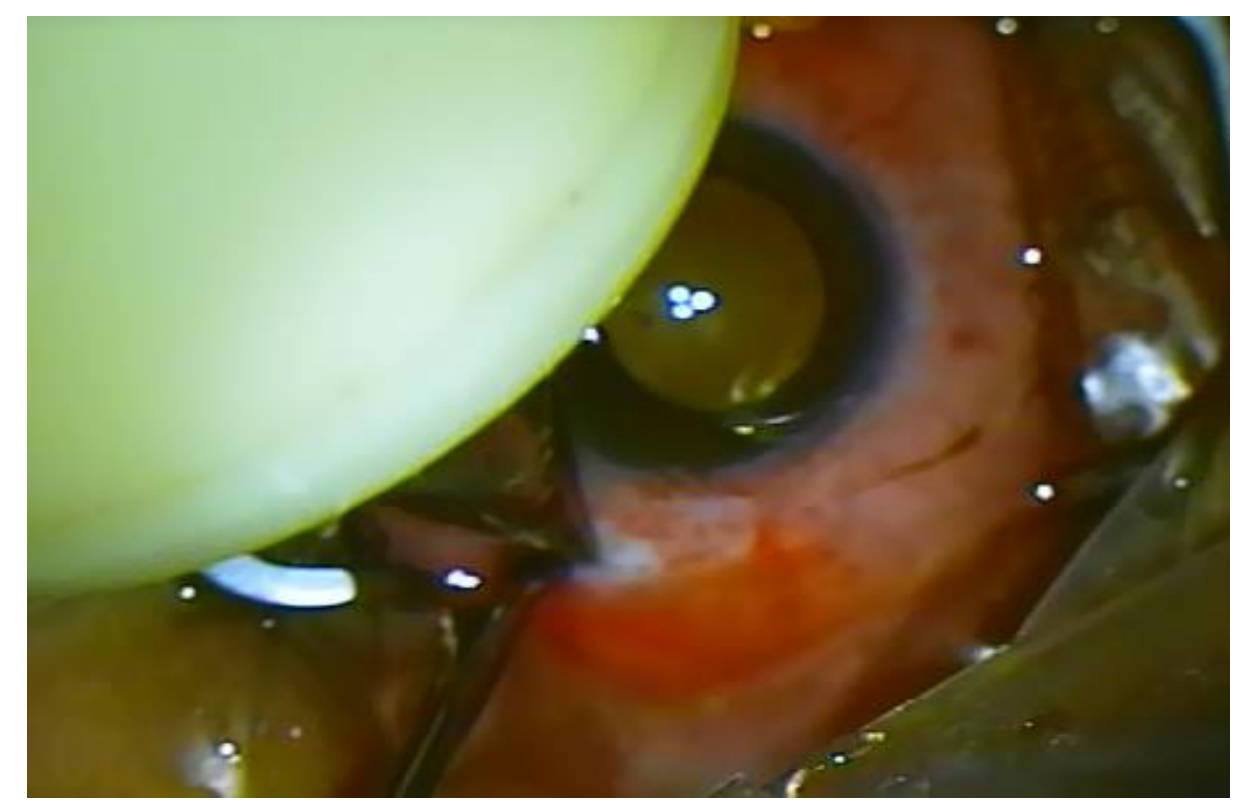

Figure 3: showing removal of IOFB through the sclerotomy with application of external magnet close to the sclerotomy. 


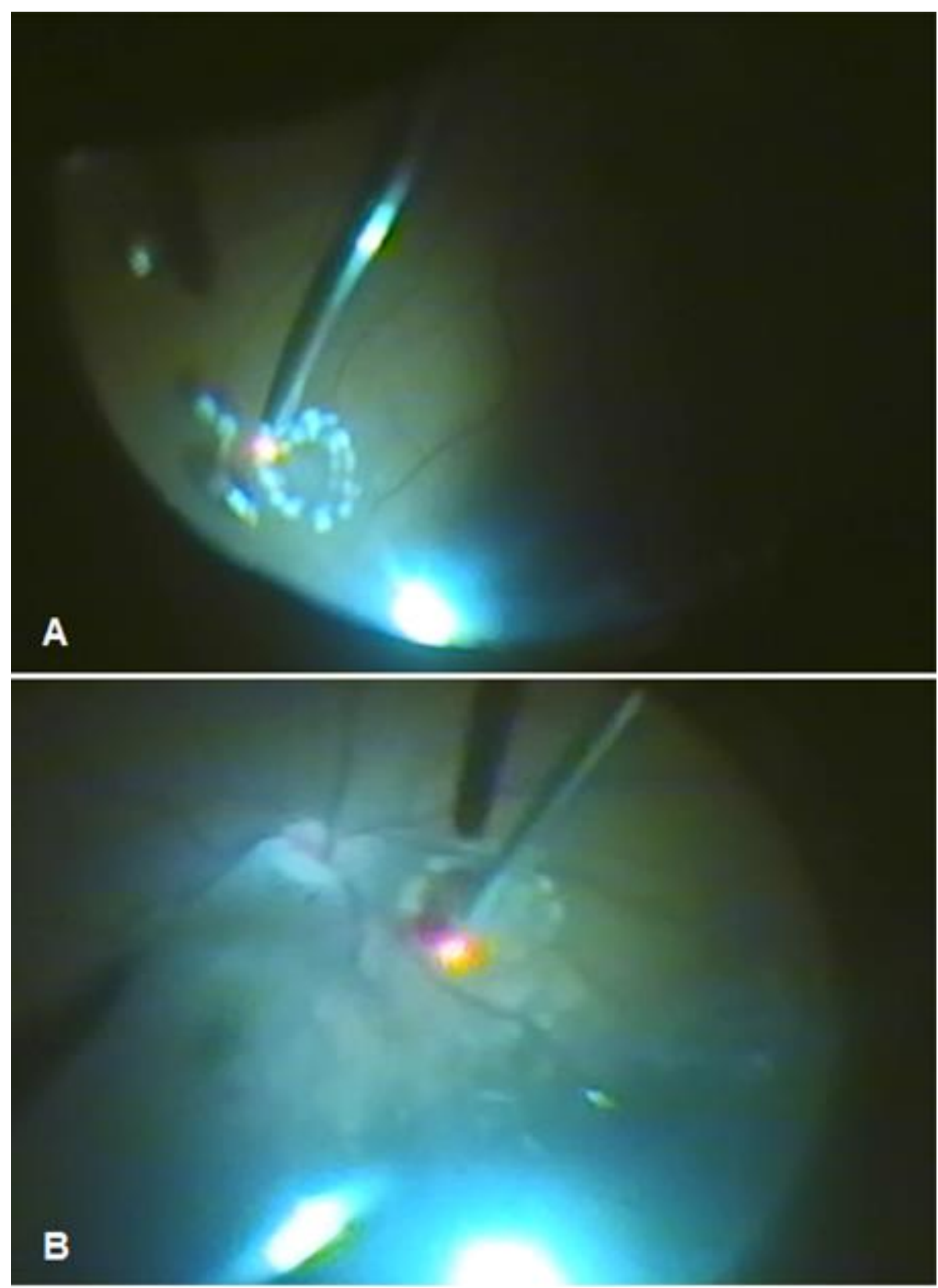

Figure 4 A \& B: showing application of endolaser photocoagulation to retinal tears.

\section{Postoperative management}

All patients received oral levofloxacin 500 mg once daily, nonsteroidal antiinflammatory drugs, systemic steroids when necessary as well as topical antibiotic, steroid and cycloplegic for four weeks with gradual tapering. In each case recording of BCVA, intraocular pressure, slit-lamp biomicroscopy and indirect ophthalmoscopy was done.

\section{Outcome evaluation}

The outcome and the follow-up data reviewed were: anterior and posterior segment sequelae after surgical procedures, BCVA, and followup period. Final BCVA was defined as BCVA after follow up period of 3 months of initial procedure or any subsequent surgery. Followup data were obtained from the outpatient charts. Prognostic Factors which were evaluated for significance included initial visual acuity, IOFB location, entry site, and presence of endophthalmitis, preoperative and postoperative RD. Three different groups were categorized according to final BCVA: Group 1: final BCVA 0.1 Snellen or less. Group 2: final BCVA ranged from 0.1 to 0.4 Snellen Group 3: final BCVA equal to or more than 0.5 Snellen. Prognostic factors were statistically studied for their significance in predicting a good visual outcome, defined as a final visual acuity of 0.5 or more, and a 
poor visual outcome, defined as a final visual acuity of 0.1 or less.

\section{STATISTICAL METHODS}

All data were collected, tabulated and statistically analyzed using SPSS 20.0 for windows (SPSS Inc., Chicago, IL, USA) and MedCalc 13 for windows (MedCalc Software bvba, Ostend, Belgium). To determine prognostic factors for good visual outcome and poor visual outcome, univariate logistic regression was done. Backward multivariate logistic regression analysis model was done using any predictor with $\mathrm{p}<0.2$ in univariate analysis. All tests were two sided. Statistically significance was considered at $\mathrm{p}<0.05$, $\mathrm{p}<0.001$ was considered highly statistically significant.

\section{RESULTS}

This study was a prospective case-series interventional study. It included consecutive eyes of 80 patients with open-globe injuries (full thickness wound of the eyeball) and retained IOFB in the posterior segment who underwent posterior segment IOFB removal by PPV at Zagazig University Hospitals between August 2013 and December 2015.

There were $74(92.5 \%)$ males and $7(7.5 \%)$ females. The age of patients ranged from 1855 years (mean $28.80 \pm 7.82$ years). There was no significant difference in patients in both good outcome and poor outcome groups regarding age and sex. Hand hammering was the cause of the injury in 37 patients $(46.25$ $\%)$ and chiseling on metal was the cause of in 32 patients $(40 \%)$.

Ocular findings on admission were iris damage or prolapse (40\%), hyphema (35\%), cataract $(47.5 \%)$, vitreous hemorrhage $(67.5 \%)$ and RD (7.5\%), siderosis bulbi $(6.25 \%)$ and endophthalmitis (10\%).

Surgery was done in the first 7 days of injury in 15 patients $(18.75 \%)$ (Cases complicated by RD, endophthalmitis, or traumatic cataract with ruptured lens capsule and secondary glaucoma), between 8 to 13 days in 38 patients $(47.50 \%)$, and the remaining 27 patients $(33.75 \%)$ had delayed surgery after 14 days.

The site of penetration was corneal in 31 eyes $(38.75 \%)$, corneoscleral in 24 eyes $(30 \%)$, scleral in 25 eyes $(31.25 \%)$. The location of the foreign body was intraretinal outside the macular area in 18 eyes $(22.25 \%)$, intraretinal in the macular area in 21eyes (26.25\%), lying on the surface of the retina in 18 eyes $(22.50 \%)$, and lying in the vitreous in 23 eyes $(28.75 \%)$.

Postoperative RD occurred in 17 patients $(21.25 \%) ; 13$ of them were saline-filled eyes and the remaining 4 cases, RD occurred under silicon. Repeated surgery was performed for the repair of a postoperative RD in 14 patients while the remaining 3 cases were inoperable. The retina was successfully reattached in 10 of the 14 eyes; 2 of them were treated by supplementary scleral buckle for inferior retinal break, and the other 8 cases were successfully reattached by revitrectomy. Proliferative vitreoretinopathy (PVR) prevented reattachment in 4 eyes.

Final BCVA was equal to or more than 0.5 (good outcome) in 28 patients, between $0.1-$ 0.4 in 20 patients and less than 0.1 (poor outcome) in 32 patients. Initial poor BCVA was found to be highly significant for poor final BCVA $(\mathrm{p}<0.001)$ as shown in Table 1.

Table 2 summarized the distribution of the prognostic factors among the good and poor outcome groups and their significance on predicting visual outcome. Age, sex of patients and preoperative RD were found to be insignificant for visual outcome. Corneoscleral entry site and intraretinal FB location were found to be highly significant for poor visual outcome $(p<0.001)$. Corneal entry site and IOFBs finally located in vitreous cavity were highly significant for good outcome ( $\mathrm{p}$-value $<0.001$ ). Presence of preoperative endophthalmitis and postoperative $\mathrm{RD}$ were found to be statistically significant for poor visual outcome $(\mathrm{p}=0.037$ and 0.006 respectively). 
Table 1 Relation between initial best corrected visual acuity (BCVA) and final BCVA.

\begin{tabular}{|c|c|c|c|c|c|}
\hline & \multicolumn{3}{|l|}{ Final BCVA $^{*}$} & \multirow{2}{*}{ Test } & \multirow{2}{*}{ p-value } \\
\hline & $\overline{<0.1(n=32)}$ & $0.1-0.4(\mathrm{n}$ & $\geq 0.5(n=28)$ & & \\
\hline \multicolumn{6}{|l|}{ Initial BCVA* } \\
\hline$-<0.1(n=32)$ & $32(100 \%)$ & $18(90 \%)$ & $16(57.1 \%)$ & $21.506 \$$ & $<0.001$ \\
\hline$-0.1-0.4(n=8)$ & $0(0 \%)$ & $2(10 \%)$ & $6(21.45 \%)$ & & \\
\hline$-\geq 0.5(n=6)$ & $0(0 \%)$ & $0(0 \%)$ & $6(21.45 \%)$ & & \\
\hline
\end{tabular}

"Snellen's fraction

* Chi-square test.

Table 2 Comparison between poor visual outcome patients and good visual outcome patients

\begin{tabular}{|c|c|c|c|c|}
\hline Parameters & $\begin{array}{l}\text { Final } \mathrm{BCVA}^{*} \\
<0.1\end{array}$ & Final $\mathrm{BCVA}^{*} \geq 0.5$ & Test & $\mathrm{p}$-value \\
\hline $\begin{array}{l}\text { Age (years), } \\
\text { Range } \\
\text { Mean } \pm \mathrm{SD} \\
\end{array}$ & $\begin{array}{l}19-38 \\
26.62 \pm 5.16\end{array}$ & $\begin{array}{l}18-55 \\
30.50 \pm 10.18 \\
\end{array}$ & $-1.636 \bullet$ & 0.102 \\
\hline $\begin{array}{l}\text { Sex; }(\mathrm{n} / \%) \\
\text { Male } \\
\text { Female } \\
\end{array}$ & $\begin{array}{l}30(93.8 \%) \\
2(6.3 \%)\end{array}$ & $\begin{array}{l}26(92.9 \%) \\
2(7.1 \%)\end{array}$ & $0.019 \ddagger$ & 0.89 \\
\hline $\begin{array}{l}\text { Entry site; }(\mathrm{n} / \%) \\
\text { Cornea } \\
\text { Sclera } \\
\text { Corneoscleral } \\
\end{array}$ & $\begin{array}{l}4(12.5 \%) \\
8(25 \%) \\
20(62.5 \%) \\
\end{array}$ & $\begin{array}{l}20(71.4 \%) \\
8(28.6 \%) \\
0(0 \%)\end{array}$ & $30.536+$ & $<0.001$ \\
\hline $\begin{array}{l}\text { IOFB location } \\
\text { Vitreous } \\
\text { On the retina } \\
\text { Intraretinal } \\
\end{array}$ & $\begin{array}{l}5(15.6 \%) \\
3(9.4 \%) \\
24(75 \%) \\
\end{array}$ & $\begin{array}{l}13(46.4 \%) \\
11(39.3 \%) \\
4(14.3 \%) \\
\end{array}$ & $22.245 t$ & $<0.001$ \\
\hline $\begin{array}{l}\text { Preoperative endophthalmitis } \\
\text { No }(n=52) \\
\text { Yes }(n=8)\end{array}$ & $\begin{array}{l}25(78.1 \%) \\
7(21.9 \%)\end{array}$ & $\begin{array}{l}27(96.4 \%) \\
1(3.6 \%)\end{array}$ & $4.329 \%$ & 0.037 \\
\hline $\begin{array}{l}\text { Preoperative retinal detachment } \\
\text { No }(n=55) \\
\text { Yes }(n=5)\end{array}$ & $\begin{array}{l}28(87.5 \%) \\
4(12.5 \%)\end{array}$ & $\begin{array}{l}27(96.4 \%) \\
1(3.6 \%)\end{array}$ & 1.558 & 0.359 \\
\hline $\begin{array}{l}\text { Postoperative retinal detachment } \\
\text { No }(n=46) \\
\text { Yes }(n=14)\end{array}$ & $\begin{array}{l}20(62.5 \%) \\
12(37.5 \%)\end{array}$ & $\begin{array}{l}26(92.9 \%) \\
2(7.1 \%)\end{array}$ & $7.693 \$$ & 0.006 \\
\hline
\end{tabular}

"Snellen's fraction

- Mann Whitney U test.

$¥$ Chi-square test.

\section{DISCUSSION}

Many factors may affect the anatomic and functional success in PPV for IOFB. The most important of these factors are entry site and location of the foreign body, and primary ocular injuries associated with IOFB ${ }^{[6]}$.

In this study, most of patients were young males $(92.5 \%)$ with a mean age of 29 years. Most of them were in the working-age group and attributed the injury to occupational exposure. We found that age and sex were statistically insignificant for visual outcome, and this is consistent with most of previous studies ${ }^{[4,5,7, \text { and } 8]}$.

Several preoperative factors have been proven to have predictive value in the visual outcome of the injured eye with retained IOFB. In this study, Initial poor BCVA was found to be highly significant for poor final BCVA. Thirty-two patients $(40 \%)$ had poor final BCVA $(<0.1)$; all of them were in the initial poor BCVA group. Initial VA had been a well 
recognized predictor of visual outcome in most of the previously published studies on

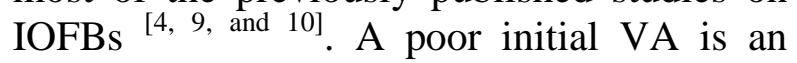
indicator of severity of ocular injury and cases of irreversible ocular damage e.g. macular and optic nerve injuries usually present with poor initial VA.

In this study, corneoscleral and sclera entry sites were statistically significant for poor visual outcome and corneal entry site was highly significant for good outcome and this is consistent with similar observations by others $[4,5]$. Corneoscleral entry sites are frequently associated with retinal injury, postoperative PVR and RD. on the other hand, the energy of the objects entering the cornea is partially or completely absorbed by tissues in the anterior segment, and these IOFBs produce less retinal damage.

In this study, IOFBs located in vitreous cavity and retina was found to be significant for good outcome, and intraretinal location was significant for poor outcome. This is in agreement with observations by others ${ }^{[4,11 \text {, and }}$ 12] who reported that IOFB location is an important prognostic factor for visual outcome.

Foreign bodies located in the posterior segment were proven to increase the risk of endophthalmitis [13]. In this study, preoperative endophthalmitis was found in 9 cases $(11.25 \%)$. Incidence of endophthalmitis in eyes with IOFBs in pevious reports ranged from $10 \%$ to $13 \%$ especially for eyes with IOFBs contaminated by organic matter in rural areas [1, 14, and 15]. In this study, Preoperative endophthalmitis was proved to be significantly associated with poor visual outcome and in spite of early vitrectomy; 7 cases had poor visual outcome and ended by atrophia bulbi and visual acuity between light perception and hand movement. Williams el al. ${ }^{[14]}$ reported that endophthalmitis was not predictive of poor outcome but most of their cases of endophthalmitis were seen within 24 hrs. of injury with prompt intravitreal antibiotics On other studies, endophthalmitis had been a well recognized predictive factor of visual outcome in injured eye with a retained IOFB $^{[5,15-17]}$.

Preoperative and postoperative RD complicated by severe proliferative vitreoretinopathy is the main cause for visual loss following IOFB injuries involving the posterior segment ${ }^{[18]}$. In this study, only 6 eyes $(7.5 \%)$ had preoperative RD. The preoperative RD was found to be insignificant factor for visual outcome. This is consistent with Falavarjani et al. ${ }^{[6]}$ who reported that preoperative RD was not a significant predictor of the development of a postoperative RD. Careful attention to the retina during removal of IOFB and the use of perfluorocarbon liquid (PFCL) for protection of the retina may lead to improved results ${ }^{[6]}$.

In this study, postoperative RD was the most major complication. Seventeen patients had postoperative $\mathrm{RD}$ and 12 of them had a BCVA less than 0.1. Postoperative RD was proven to be a statistically significant for poor visual outcome. According to several reports $[4,8,19,20]$, postoperative $\mathrm{RD}$ was associated with poor final $\mathrm{BCVA}$ and considered a strong predictor of poor visual outcome.

In conclusion, various preoperative, operative, and postoperative Factors were identified to help predicting visual outcome after pars plana vitrectomy for posterior segment IOFB. Age, sex of patients and preoperative RD were found to be insignificant for visual outcome. Initial poor BCVA was found to be highly significant for poor final BCVA. Corneoscleral entry site and intraretinal FB location were found to be highly significant for poor visual outcome. Corneal entry site and IOFBs finally located in vitreous cavity were highly significant for good outcome. Presence of preoperative endophthalmitis and postoperative RD were found to be significant for poor visual outcome.

\section{REFERENCES}

1- Thompson JT, Parver LM, Enger CL, et al.. Infectious endolphthalmitis after penetrating injuries with retained foreign bodies. Ophthalmology; 1993; 100:1468-1474.

2- McCabe CM, Mieler WF, Postel EA . Surgical management of intraocular foreign bodies. In: Alfano PV, Ligett PE, eds. Vitreoretinal Surgery of the Injured Eye. Philadelphia, PA: Lippincott-Raven; 1999 : 257-270.

3- Soheilian M, Ahmadieh H, Sajjadi H, et al. Temporary keratoprosthesis for surgical management of complicated combined anterior and posterior segment injuries to the eye: 
combat- versus noncombat-injury cases. Ophthalmic Surg; 1994: 25:452-457.

4- Wani VB, Al-Ajmi M, Thalib L, et al. Vitrectomy for posterior segment intraocular foreign bodies: visual results and prognostic factors. Retina;2003: 23:654-660.

5- Zhang Y, Zhang M, Jiang C, et al. Intraocular foreign bodies in China: clinical characteristics, prognostic factors, and visual outcomes in 1421 eyes. Am J Ophthalmol; 2011:152:66-73.

6- Falavarjani KG, Hashemi M, Modarres M, et al. Vitrectomy for posterior segment intraocular foreign bodies, visual and anatomical outcomes. Middle East Afr J Ophthalmol; 2013: 20:244-247.

7- Szijártó Z1, Gaál V, Kovács B, Kuhn F. Prognosis of penetrating eye injuries with posterior segment intraocular foreign body. Graefes Arch Clin Exp Ophthalmol; 2008: 246:161-165.

8- Öztaş Z, Nalçacı S, Afrashi F, et al. Posterior segment intraocular foreign bodies: the effect of weight and size, early versus late vitrectomy and outcomes. Ulus Travma Acil Cerrahi Derg; 2015: 21:496-502.

9- Greven CM, Engelbrecht NE, Slusher MM, et al. Intraocular foreign bodies: management, prognostic factors, and visual outcomes. Ophthalmology; 2000: 107:608-617.

10- Chaudhry IA, Shamsi FA, Al-Harthi E, et al. Incidence and visual outcome of endophthalmitis associated with intraocular foreign bodies. Graefes Arch Clin Exp Ophthalmol; 2008: 246:181-186.

11- Chiquet C, Zech JC, Gain P, et al. Visual outcome and prognostic factors after magnetic extraction of posterior segment foreign bodies in 40 cases. Br J Ophthalmol; 1998: 82:801-806.

12- Chow DR, Garretson BR, Kuczynski B, et al. External versus internal approach to the removal of metallic intraocular foreign bodies. Retina; 2000: 20:364-369.

13- Duch-Samper AM, Menezo JL, HurtadoSarrió M. Endophthalmitis following penetrating eye injuries. Acta Ophthalmol Scand; 1997: 75:104-106.

14- Williams DF, Mieler WF, Abrams GW, et al. Results and prognostic factors in penetrating ocular injuries with retained intraocular foreign bodies. Ophthalmology; 1988: 95:911-916.

15- Choovuthayakorn J, Hansapinyo L, Ittipunkul $\mathrm{N}$, et al. Predictive factors and outcomes of posterior segment intraocular foreign bodies. Eye; 2011: 25:1622-1626.

16- Affeldt J, Flynn HW Jr, Forster RK et al. Microbial endophthalmitis resulting from ocular trauma. Ophthalmology; 1987: 94:407-413.

17- Lieb DF, Scott IU, Flynn HW Jr, et al. Open globe injuries with positive intraocular cultures: factors influencing final visual acuity outcomes. Ophthalmology; 2003: 110:1560-1566.

18- El-Asrar AM, Al-Amro SA, Khan NM, Kangave D. Retinal detachment after posterior segment intraocular foreign body injuries. Int Ophthalmol; 1998: 22:369-375.

19- Demircan N, Soylu M, Yagmur M, et al. Pars plana vitrectomy in ocular injury with intraocular foreign body. J Trauma; 2005: 59:1216-1218.

20- Wickham L, Xing W, Bunce C, et al. Outcomes of surgery for posterior segment intraocular foreign bodies- a retrospective review of 17 years of clinical experience. Graefes Arch Clin Exp Ophthalmol; 2006: 244:1620-1626. 